\title{
MANAGEMENT DEVELOPMENT
}

$\mathrm{A}^{\mathrm{T}}$ T a conference organized by the British Institute of Management at Harrogate during January 22-24, more than a hundred representatives from leading industrial organizations in Britain discussed the finding and development of managers for industry.

To open the conference, Mr. E. F. L. Brech, of Urwick, Orr and Partners, examined the motives which cause young men to choose a managerial career. The goal could be money, the idea of power, prestige, or a wish to cover up the man's sense of inferiority. Mr. Brech suggested that these reasons are inadequate. The essence of management is responsibility for a social task, and the better educated mind should be attracted to management with the offer of a satisfying social job rather than for the financial return.

He wondered whether the advertisements selling the idea of a big and lucrative future in management were carrots to draw in bright young men who would not be given a chance to get ahead. Many men now in top managerial posts should not be there, and firms should keep their eyes open and remove incompetent men before they got too far. The responsibility of management is to do the job efficiently and economically. Good human relations lead to good morale and so help to achieve this end.

Here, Mr. A. Brown, administration and personnel director, Mars, Ltd., suggested that all companies should adopt an appraisal system to ensure that all human resources in the company are looked at systematically at least once a year. The right man, the best man for the job, should be sought within and without the company.

If the company needs a 'go-getter', then he should be sought. If the company needs a systematic, conservative type, he should be looked for. Small and medium-sized firms must often rely on large firms to train managers who will either find inadequate or too distant scope in those firms and seek work in the smaller company with its close relationships and opportunity for wide experience.

When selecting men as managers there must be not only a job specification but also $\mathbf{a}_{\mathrm{a}}$ full definition of the requirements of the job in relation to the organization, its personnel and future planned development. It is desirable to know who the man will work with. Is a systematic or intuitive approach required in the job as envisaged? These are the kind of facts which should be known but rarely are.

If the company has a natural successor for an appointment, it should dispense with elaborate selection methods. If the company is satisfied that it has the right man after examining all information and records, the selection should be made there and then.

Mr. W. W. Ferguson, of James Williamson and Son, Ltd., suggested that, to find the right man, the old Army custom of making men into acting tem. porary unpaid lance-corporals should be tried on the shop floor. In this way, argued Ferguson, it could be discovered whether the prospective foreman was a good leader and, by letting him work with a carefully chosen foreman, he could be seen in action. If he were satisfactory, all would be well; if not, he could be returned to his previous job.

This assumption was not generally accepted. One or two delegates supported Mr. Ferguson, but many others rejected his plan as impractical. Most of the delegates felt that in industry it was no easy thing to lower a man's status after raising it, and that the temporary foreman would suffer as he could have no real authority during his trial period.

In an informal discussion, the conference considered a suggestion that the end of National Service would be the end of an interlude which did much useful work in disciplining the nation's industrial recruits. More than one speaker claimed that industry could get along quite well without this service, and that it could undertake its own teaching of discipline and training of apprentices.

One of the general conclusions emerging from the conference was that management development is supported only by a representative, sincere and progressive slice of British industry. More than once voices were raised to ask whether top managementthe policy makers and leaders of industry-was yot sufficiently convinced of its practical value.

Examples were given of firms with comprehensive management development programmes sympathetically encouraged by the men at the top : so were more cynical views that top management thought such programmes a waste of their valuable time. T. H. HAwkins

\section{ELECTRON MICROSCOPISTS}

\begin{abstract}
A $T$ the fifteenth annual meeting of the Electron Microscope Society of America, which was held at the Massachusetts Institute of Technology on September 11, 1957, the president, Dr. J. H. L. Watson, head of the physics department of the Edsel B. Ford Institute for Medical Research (Henry Ford Hospitial, Detroit 2, Michigan), gave a summary of the results and conclusions of a survey which he had recently conducted on the subject of what was expected professionally of a trained electron microscopist. The survey was made by questionnaire and letter addressed to two hundred electron microscopists and directors or supervisors of laboratories in which
\end{abstract}

electron microscopy is used. One hundred and thirtynine answers and opinions were received, but despite the diverse fields of application in the various institutions the replies showed a surprising unanimity.

A good laboratory attitude, a co-operative personality, scientific imagination, and patience, were the particular personal qualities required. Familiarity with the particular field of application, in addition to electron microscopy, was stressed, as was also the importance of ability to inform others clearly and concisely of the work in progress. No desire was expressed by the biologists or non-biologists for a difference in treining of scientists for electron micro- 